\title{
MORTE DO HOMEM BRANCO E POTÊNCIA-SENZALA: TRADUÇÃO EM TEMPO DE NOVAS ONTOLOGIAS
}

\author{
Leandro T. C. Bastos $\underline{1}$ \\ -Universidade de São Paulo, São Paulo, São Paulo, Brasil
}

\begin{abstract}
Resumo: Badiou, em $O$ Ser e o Evento, parte do princípio que o vazio é formado por multiplicidades inconsistentes. Essa visão impossibilita a concepção de uma unidade fechada. Acreditamos que tal formulação se mostra como um corolário filosófico importante de formulações que estão sendo feitas na antropologia. Roy Wagner, em sua obra An Anthropology of the Subject, vai formular a ideia de sujeito holográfico, sublinhando a impossibilidade de distinguir formulação e vivência. Marilyn Strathern, com seu questionamento em relação às escalas, no seu livro Partial Connections, vai na mesma direção. Podemos pensar o afastamento do modelo de sujeito unitário tanto como causado pelo enorme processo de tradução para a língua dominante que aconteceu graças à globalização, como pelo estudo de narrativas de outras culturas, com outros modelos de sujeito, como nos estudos citados acima e demais esforços da antropologia. Ao contrário de uma integração institucional, esse tipo de encontro tradutório está levando a uma série de tensões que torna a fórmula de Viveiros de Castro, o multinaturalismo, numa reflexão central: não vivemos apenas em diferentes culturas, mas em diferentes mundos.
\end{abstract}

Palavras-chave: Tradução; Ontologia; Políticas do Sujeito; Globalização

\section{THE DEATH OF THE WHITE MAN AND SLAVE QUARTER'S POWER: TRANSLATION IN TIMES OF NEW ONTOLOGY}

\begin{abstract}
Badiou, in Being and Event, assumes that the void is formed by inconsistent multiplicities. This view precludes the conception of a closed unit. We believe that such a formulation proves to be an important philosophical corollary to formulations being made in anthropology.
\end{abstract}


Roy Wagner, in his book An Anthropology of the Subject, will formulate the idea of the holographic subject, underlining the impossibility of distinguishing between formulation and experience. Marilyn Strathern, with her discussion about scales, in her book Partial connections, goes in the same direction. We can think of the departure from the unitary model of subject as caused as much by the enormous process of translation into the dominant language that happened thanks to globalization, as by the study of narratives from other cultures, with other models of subject, as in the studies cited above and other efforts. of anthropology. Unlike an institutional integration, this kind of translational encounter is leading to a series of tensions that makes Viveiros de Castro's formula, multinaturalism, a central reflection: we live not only in different cultures, but in different worlds.

Keywords: Translation; Ontology; Policies of the Subject; Globalization

No presente artigo iniciaremos por traçar, de modo geral, como o pensamento de Alain Badiou estrutura a questão da ontologia. Em seguida faremos paralelos entre esse pensamento e o de Henri Meschonnic. Tal aproximação permite iniciar pela chamada filosofia primeira, ontológica, e avançar para a maneira como Meschonnic trabalha a antropologia e, principalmente, a linguagem, incluída aí a tradução. Por fim, apontaremos algumas possibilidades de conexão com o pensamento antropológico contemporâneo, principalmente o de Roy Wagner, Marilyn Strathern e Eduardo Viveiros de Castro. Apesar de parecer um espectro muito amplo, teremos um ponto em comum a todas essas abordagens: as respectivas concepções de sujeito. A partir dela é que poderemos falar do papel da tradução nesse panorama.

Essa abordagem nos parece importante porquê esse tipo de diálogo já vêm acontecendo entre a antropologia e a tradução de forma mais intensa. Se na virada ontológica da antropologia a tradução aparece desde o primeiro momento, o percurso se mostra mais oblíquo em relação à ontologia mais recente na filosofia. Senão vejamos. No diálogo com o existencialismo, George Steiner encontra em Heidegger um lugar em que a tradução desvela uma espécie de língua originária sempre inacessível, em clara referência à clareira do Ser em relação ao Ser-aí heideggeriano. Em Levinas, a questão 
ética traz grande relevância à tradução. Sua abordagem, no entanto, se afasta da ontologia e se aproxima do misticismo judaico. De modo parecido, Walter Benjamin também mescla misticismo judaico e abordagem social em seu fundamental $A$ tarefa do tradutor. Sua perspectiva social, no entanto, é feita sob pressupostos marxistas. Na antropologia, por outro lado, Viveiros de Castro, de maneira mais transformadora, diríamos, canibalística, usa conceitos de Deleuze de modo mais pontual, antes levando suas referências antropológicas, junto a Guatarri, presentes no Anti-Édipo e nos Mil platôs, a dialogar com seu multinaturalismo. O pensamento deleuziano aparece antes cotejado com as formulações de Viveiros, de modo a expandi-las, do que dão origem a essas formulações.

Nesse brevíssimo apanhado encontramos o que, em relação ao eixo da nossa argumentação, o sujeito, chamaremos de pensamento de oclusão. Tanto no existencialismo como no pós-estruturalimo vemos o sujeito iluminista, íntegro e autorreferente, sendo posto em xeque. Como poderíamos ver a tradução num contexto ontológico posterior, em que o sujeito se mostra de maneira totalmente diversa? É isso que encontramos em filósofos como Latour e Badiou. É em relação a esse último que estaremos nos reportando.

Badiou inicia $O$ Ser e o Evento diagnosticando a atual situação. Por um lado, na filosofia, encontra tanto em Heidegger como na maneira como a racionalidade científica influencia a filosofia analítica os limites de um pensamento baseado no logos. Por outro, evoca fatores externos:

Está em desenvolvimento uma doutrina pós-cartesiana do sujeito, cuja origem pode ser atribuída a práticas não filosóficas (a política, ou a relação instituída com as 'doenças mentais'), e cujo regime de interpretação, marcado pelos nomes de Marx (e Lenin), de Freud (e Lacan), está enredado em operações, clínicas ou militantes, que excedem o discurso transmissível. (Badiou 11) 
Vê, portanto, o "fecho de uma época inteira do pensamento". Esses limites se mostram pela impossibilidade de uma "doutrina do nó ser/não-ser/pensamento" (Badiou 12), ou, como poderíamos complementar, pela separação entre sujeito e objeto. De fato, Badiou vai dizer que

esse tema da verdade atravessa Heidegger (que é o primeiro a subtraí-lo ao saber), os matemáticos (que no fim do século passado rompem tanto com o objeto quanto com a adequação) e as teorias modernas do sujeito (que excentram a verdade de sua pronunciação subjetiva). (Badiou 13)

Nessa passagem, Badiou faz referência explícita a Heidegger, e implícita a Cantor e Lacan. Como consequência dos fatores mencionados, "o Sujeito contemporâneo é vazio, clivado, a-substancial, irreflexivo. Aliás, Ele pode apenas ser suposto no tocante a processos particulares cujas condições são rigorosas" (Badiou 12).

A partir das condições apresentadas, Badiou conclui que se "a lógica pura era 'ciência do real', o real continua sendo, contudo, uma categoria do sujeito." (Badiou 13) O sujeito contemporâneo, "vazio e clivado", vai ser apresentado pela ontologização da matemática, mais especificamente, da teoria dos múltiplos transfinitos, de Cantor. De maneira muito, mas muito simplificada, podemos dizer que a noção de conjunto cantoriana, pelo menos aquela que será mais largamente aproveitada por Badiou, é de que estamos o tempo todo falando de múltiplos compostos de outros múltiplos. Mesmo o que chamamos de vazio seria apenas um regime de multiplicidade inconsistente, não apresentada ao pensamento. "Inconsistência" e "apresentação" estão, por isso mesmo, entre os conceitos fundamentais de Badiou. Após apresentada, a multiplicidade se configura como uma "situação". Segundo Badiou: "chamo situação toda multiplicidade apresentada." (Badiou 30) Para que o pensamento se configure, é preciso que a multiplicidade da apresentação seja tirada de sua inércia e mostrada enquanto possibilidade estrutural. 
Esse processo Badiou vai chamar de "conta-por-um”. Isso porque, na apresentação, os múltiplos em si são inconsistentes. O processo de conta-por-um lhes confere consistência que pode ser estruturada, ou melhor, em que já configuram, potencialmente, estruturas de pensamento. Segundo Badiou, "Toda situação admite um operador de conta-por-um, que lhe é próprio. É a definição mais geral de uma estrutura ser o que prescreve, para uma multiplicidade apresentada, o regime da conta-por-um."(Badiou 30) Após o processo de conta-por-um, os múltiplos saem da apresentação (inconsistente) e entram para a composição (consistente): “[...] lá uma multiplicidade de inércia, a da apresentação, e uma multiplicidade de composição, que é a do número e do efeito da estrutura.” E aqui temos a primeira divisão fundamental no regime da multiplicidade: "Convencionemos chamar multiplicidade inconsistente, a primeira, e multiplicidade consistente, a segunda." (Badiou 30)

O processo de conta-por-um, de formação da consistência, implica, portanto, na seleção de um arcabouço, seleção essa que exclui multiplicidades na apresentação infinita de múltiplos. "Por si mesmo, o nada não é senão o nome da inapresentação na apresentação." (Badiou 52) Possibilidade constituinte da composição, presente na sua própria base, é essa característica da apresentação, especificamente ontológica (só o que se liga ao vazio é ontológico, Badiou vai argumentar) que irá permitir que qualquer evento não se prenda ao determinismo: "se o vazio é tematizado, é preciso que ele o seja na apresentação de sua errância.” (Badiou 53)

O passo seguinte de Badiou é determinar as condições em que os múltiplos podem se combinar para formação de estruturas. Para isso utiliza cinco axiomas. O primeiro é o da extensionalidade, que diz respeito à determinação e à delimitação de um múltiplo em relação a outro (Badiou 56). Os outros quatro, apesar de possuírem especificidades que fogem ao senso comum de seus nomes, ainda compartilham características o bastante com nossa compreensão mais imediata para que não precisemos esmiuçar, aqui, suas definições. Tratam-se dos axiomas da união, da separação, da substituição e da possibilidade de formar subconjuntos (Badiou 57). Por 
meio desse jogo distributivo poderíamos, segundo Badiou, descrever as estruturas do ser, seja qual for o nível em que se apresente.

Enquanto falamos das propriedades básicas dos conjuntos estamos falando de apresentação. A partir do momento em que começamos a falar dos conjuntos já combinados, passamos a falar de representação: “Toda situação é duas vezes estruturada. Isto quer dizer também: há sempre, ao mesmo tempo, apresentação e representação." (Badiou 83) Isso se dá justamente pelas diferentes combinações entre os múltiplos. Em algumas combinações, como na formação de subgrupos, estamos falando de inclusão, ou seja, os elementos que pertencem a um subgrupo estão totalmente incluídos no grupo maior em que o subgrupo se encontra. Em outras combinações, como na propriedade da união, estamos falando de pertença, ou seja, os múltiplos fazem parte da mesma conta-por-um, pertencem a mesma estrutura, mas nem todos os elementos de um subgrupo pertencem ao grupo que o contém. Temos aí a instituição de uma diferença fundamental entre inclusão e pertença (Badiou 85).

Temos de um lado uma estrutura inicial, que vale pela pertença, e, de outro, responsável pelo domínio das partes, uma meta-estrutura, que vale pela inclusão. Essa meta-estrutura se chama "estado de uma situação" (Badiou 85). Essa divisão, segundo Badiou, seria "a chave da análise do ser" (Badiou 86). Vale, portanto, uma retomada geral.

Os múltiplos infinitos, na sua inconsistência imediata, passam pela estruturação da conta-por-um, passando a pertencer a uma apresentação comum, tornando-se consistentes para a composição (pertença). As possibilidades de composição serão dadas por uma meta-estrutura que irá incluir esses múltiplos no mesmo estado de situação (inclusão). Temos aí os níveis da estrutura e da meta-estrutura do ser. O primeiro se chama apresentação, o segundo se chama representação. Entre as duas se instala um descompasso. Isso porquê, dentro de um estado de situação, podemos ter múltiplos que estão completamente nele incluídos, isto é, todos os elementos desses múltiplos pertencem ao referido estado, mas também podemos encontrar estados de situação em que seus múlti- 
plos pertencem ao referido estado, mas cujos elementos não estarão totalmente aí inclusos. É daí que Badiou deriva suas definições dos tipos de ser:

temos, de fato, no espaço completo, isto é, estatizado, de uma situação, três tipos fundamentais de termos-uns: os normais, que são apresentados e representados, os singulares, que são apresentados e não representados, e os excrescentes, que são representados e não apresentados. (Badiou 87)

O primeiro tipo de ser diz respeito à natureza. Nela, todos os elementos de seus múltiplos são apresentados e representados. Não há excessos nem ilusões. Diferente, para Badiou, é o caso da história:

\begin{abstract}
É plausível pensar o a-normal, a antinatureza, portanto a história, como onipresença da singularidade - assim como pensamos a natureza como onipresença da normalidade. A forma-múltipla da historicidade é o que está inteiramente no instável do singular, aquilo sobre o que a metaestrutura estática não pode agir. É um ponto de subtração à reafirmação da conta pelo estado. (Badiou 144)
\end{abstract}

$\mathrm{Na}$ história, portanto, sobram elementos em busca de representação. A situação da excrescência, em que mais elementos são representados do que efetivamente apresentados, é a do cotidiano.

Ora, se os únicos múltiplos com todos os elementos inclusos são os naturais, a história se torna sempre incompleta, parcial, e seus critérios serão sempre locais. Isso exige o que Badiou chama de uma "topologia diferencial da ação". O modo de se articular essa topologia vem no axioma da "intervenção". Para o autor, "intervenção consiste, ao que parece, em apontar que houve indecidível, e decidir sua pertença à situação." (Badiou 166) Após isso o múltiplo se torna histórico, quer dizer, um evento: "Chamo intervenção 
todo procedimento pelo qual um múltiplo é reconhecido como evento." (Badiou 165) É através de um ato exterior aos eventos, portanto, que múltiplos históricos eventurais se configuram como eventos, como acontecimentos de sentido histórico. Após ser organizado, ganhar sentido próprio, o evento passa a ser dominado por outro axioma, o da fidelidade.

É nesse momento que podemos retomar as condições para a formação do sujeito mencionadas de início: "chamarei sujeito o próprio processo da ligação entre o evento (portanto, a intervenção) e o procedimento de fidelidade." (Badiou 183) O sujeito seria o momento, o ponto, em que as possibilidades abertas à história em toda sua multiplicidade (chamada de enciclopédia) ganha sentido num ato de intervenção. Esse ato é ontológico, pois não pertence às possibilidades já vislumbradas nos próprios múltiplos históricos, mas se enraíza no vazio. É aí que surge uma nova fidelidade, e é aí que se configura o sujeito. Por isso mesmo Badiou diz: "Fidelidade não pode depender só do saber. Não se trata de um trabalho erudito: trata-se de um trabalho militante." (Badiou 261) É fundamental nessa definição o fato de a intervenção vir do vazio. Isso, como já dito, garante seu caráter ontológico, mas garante também que não se confunda a intervenção com uma arbitrariedade de um indivíduo autônomo. O indivíduo cria um processo de fidelidade, configurando eventos históricos através da intervenção, mas ele também é criado pela intervenção. Antes disso, nossa condição de individuo não está assegurada. Antes disso integramos múltiplos entre múltiplos.

É na aliança entre procedimento e fidelidade que pode aparecer a verdade. Categoria ontológica, se diferencia do verídico, mera constatação de fatos dentro da enciclopédia. Tratasse, portanto, de uma categoria do sujeito. A verdade aparece em três situações: no amor, no par arte/ciência e na política. Nos três casos o sujeito se põe entre o vazio e um procedimento. No caso do amor há um outro sujeito, no da arte/ciência há um material específico e na política há a coletividade.

Nesse panorama, podemos fazer uma aproximação com Meschonnic. Em ambos os sistemas temos uma distribuição com alto 
grau de liberdade, mas não dispersa, de material (os múltiplos num caso, o ritmo em outro) e uma força que é ao mesmo tempo aberta e interventora, nas respectivas concepções de sujeito.

Segundo Meschonnic, quando Benveniste faz a crítica da etimologia que constitui o sentido corrente de ritmo, ele fez com o que o ritmo saísse do domínio dual do signo e entrasse no domínio do discurso. É aí que Meschonnic antropologiza o ritmo, que este passa a ser constituinte do, e constituído pelo, sujeito. Seu papel é o de uma organização do discurso, onde um sujeito se põe dentro e contra uma história. (Meschonnic 70) Esse “dentro e contra” denota, novamente, o caráter poroso e ativo do sujeito. Mas, assim como os múltiplos não se distinguem de modo substancial da intervenção, mas apenas através de um axioma, para Meschonnic ritmo e sujeito se interpenetram. O ritmo no sentido e no sujeito, e vice-versa, faz com que o ritmo esteja presente, e seja apresentado, por ambas as instâncias o tempo todo (Meschonnic 72) É nessa interpenetração que se chega num terceiro termo, para Meschonnic, a antropologia, apresentada na linguagem pelo elemento capital que é o ritmo (Meschonnic 73).

Apesar de todas as diferenças (e as demarcações entre autores dessa estatura é algo que foge do âmbito desse artigo) a aproximação nos pareceu necessária. Tendo a intenção de aproximar a tradução da ontologia, buscar apoio num dos pensamentos que mais desenvolveu a amplitude da tradução, e noutro, um dos que melhor desenvolveu os fundamentos da ontologia, pareceu inevitável. Mas já falamos de uma ontologia que vai até a história e chega no sujeito, e de uma história que passa pelo sujeito e chega à antropologia. Falaremos agora de antropologias que se aproximam da ontologia.

Vimos como, tanto em Badiou como em Meschonnic, encontramos um sujeito descentrado que aparece como parte e ao mesmo tempo como intervenção num sistema. Em Roy Wagner, isso aparece em dois livros.

Em The Invention of Culture, Wagner desenvolve o conceito de "obviação". Parte do princípio que em toda a cultura existem contextos coletivos que dão sentido às experiências humanas. Es- 
tabelecer a maneira como sujeito e objeto se relacionam num todo maior é a função da "obviação", fornecendo um contexto. A troca entre contextos será chamada do "objetificação". Entre ambos se estabelece uma relação dialética, "o coletivo é diferenciado e o indivíduo é coletivizado".

\begin{abstract}
Um controle desse tipo é fornecido pela discriminação ideológica aguda e vinculativa feita entre os dois modos simbólicos em todas as tradições humanas. Ou o modo convencional abstrai-se como o domínio apropriado da ação humana, deixando o modo de diferenciação como o reino do inato, ou dado, ou então o convencional se abstrai como o inato e, assim, designa a diferenciação como o modo apropriado à ação humana. ${ }^{1}$ (Wagner 40 )
\end{abstract}

A expressão que nos interessa aqui aparece nas duas formulações: "apropriado à ação humana”. O que Wagner chama de "objetificação" e "obviação" se aproxima do que Badiou chama de enciclopédia e determinação, assim como o que Meschonnic chama de ritmo e sujeito. De um lado a variedade de informações e de outro um princípio de intervenção (em si mesmo aberto à própria variedade). Novamente enfatizamos que existem diferenças que não serão aqui abordadas. Nossa intensão agora é apenas propor um diálogo. As diferenças, no entanto, são ilustrativas da discussão. Podemos localizá-las principalmente no ponto em que os princípios assinalados se separam. Em todos os casos encontramos como problema assinalar uma distinção sem que com isso se chegue a uma essencialização de nenhum dos lados, ou o de garantir uma

\footnotetext{
${ }^{1}$ Control of this sort is provided by the sharp and binding ideological discrimination made between the two symbolic modes in all human traditions. Either the conventional mode abstracts itself out as the proper realm of human action, leaving the differentiating mode as the realm of the innate, or given, or else the conventional abstracts itself off $a$ s the innate, and thus designates differentiation as the mode appropriate to human action. (Wagner 40) (tradução minha)
} 
confluência sem que um polo sufoque o outro. A obra de Wagner é bastante ilustrativa nesse sentido. Se em The Invention of Culture ele vai focar na diferenciação, em An Anthropology of the Subject é a confluência que vai ganhar destaque.

Se a formação cognitiva e subjetiva de um mundo-da-pessoa e a articulação objetiva dessa 'pessoa' como personalidade, comportamento e relacionamento no mundo são variáveis co-dependentes e co-relativas, então a formulação definitiva ou 'fixação' de um deles torna o outro aberto ao perigo e mistificação. ${ }^{2}$ (Wagner 27)

É justamente a formação holográfica entre signo e pessoa, o fato de todos os pontos do holograma estarem sobre a lâmina ao mesmo tempo, que o autor irá destacar.

Outra definição que vai numa direção parecida é a de Marilyn Strathern, quando trata cultura e sujeito como diferentes enfoques sobre um mesmo contínuo: "[...] como uma constelação de elementos, cada posição gera uma elaboração posterior com um efeito de aumento ou diminuição na constelação da posição anterior." ${ }^{3}$ (Strathern 108). Não por acaso, Strathern se volta para a mais radical demonstração da interação entre múltiplos conhecida: os múltiplos de Cantor.

A filosofia de Badiou nos pareceu interessante, nesse contexto, por ter trazido a versão mais direta das interações matemático-conceituais a emergirem nas concepções contemporâneas de sujeito. Ao perceber que, quando o sujeito move o ritmo, segundo

\footnotetext{
${ }^{2}$ If the cognitive and subjective formation of a world-in-theperson and the objective articulation of that "person" as personality, behavior, relationship in the world are co-dependent and co-relative variables, then the definitive formulation or "fixing" of one of them throws the other open to hazard and mystification. (Wagner 27) ${ }^{3}$ a constellation of elements, each position generates a further elaboration with an enlarging and diminishing effect on the constellations of the previous position. (Strathern 108) (tradução minha)
} 
Meschonnic, ele está, segundo Badiou, criando um novo múltiplo através de uma nova conta-por-um, a importância da tradução fica clara. Se estamos saindo da época do humanismo burguês, a presença de traduções na criação de um novo panorama será, no mínimo, tão importante quanto foi na entrada dessa era, durante o renascimento. De início é preciso criar deslocamentos, abalar as combinações anteriores, para que novas sínteses possam ser propostas. Esse papel, nas academias de Florença e Veneza, foi feito pela tradução. A entrada da cultura grega e latina na Europa ajudou a relativizar e reorganizar o mundo cristão medieval. Mas que deslocamentos precisam ser feitos, e como a tradução já pode estar nos ajudando?

Segundo Latour, o ocidente se constituiu sobre a distinção ciência/política. A segunda estaria subordinada à primeira (Latour 19). Isso levou à separação sujeito/objeto, e todos os seus correlatos: sujeito e meio, sujeito e sociedade, sujeito e outro sujeito. Muito da exploração do ambiente, além da exploração social, é justificada a partir dessa perspectiva.

Como coloca Robert Kurz, as contraposições acima referidas indicam "a dissolução do mundo sensível na abstração realista da forma valor." Historicamente se manifestam como o desenraizamento e o desenraizado, a tradição agrária e a desterritorialização, a razão abstrata do valor e os afetos do sujeito. Para Kurz a forma valor, enquanto sujeito automático "se impõe aos indivíduos como nexo global de relações dominadoras e autônomas, como totalidade fetichista" (Kurz 154), resultando "abstrata e tenebrosamente vazia de conteúdo, cujo incessante e objetivado automovimento gira sobre a natureza e a sociedade." Esse seria também o movimento dos "portadores individuais e institucionais" e, portanto, o da "própria forma de subjetividade ou a forma sujeito". (Kurz 154) Essa forma seria "estritamente masculina e desagregadora: o sujeito da lógica do valor e da cisão." Essa forma assumiria sua feição econômica com Adam Smith e Jeremy Bentham. Os ingleses cuidaram da feição do homo economicus. O aspecto jurídico existencial da república burguesa seria obra dos pensadores 
franceses pós 1789, como Montesquieu e o Espírito das Leis. Os alemães, sobretudo Kant e Hegel, teriam exposto a forma abstrata da ontologia do sujeito como essencial às polaridades acima referidas. É justamente o processo de produção de mais-valia ligado à racionalidade ocidental que vemos entrando em decadência, e a isso chamaremos de "a morte do homem branco", no sentido de que uma era baseada na ampliação da forma europeia de produção e pensamento se encontra em ocaso.

Diante disso, quando um antropólogo demonstra que, em determinada sociedade a condição do sujeito é intrinsecamente ligada a uma situação do ambiente, isso propõe uma reorganização profunda em nosso próprio modo de existência. O mesmo pode ser dito em relação a outros modelos de relação social, em que indivíduo e sociedade se mostram mais como problema de escala, como diria Strathern, do que como divisão fundamental. Cada aproximação, cada ponte construída entre visões de mundo até então distantes se torna um novo ritmo, um novo elemento de um múltiplo, um novo dente nas engrenagens que estão a propor outros sujeitos. Por isso a tradução tem uma vocação antropológica $e$ ontológica. Ela provoca, antecipa e ajuda a construir novos modos de existência, novos sujeitos. Para falar como Badiou, ela ajuda a trazer novos elementos para a enciclopédia de múltiplos da história. No entanto, também é preciso submeter esses múltiplos a novas possibilidades de determinação, senão o processo histórico não se constitui, quer dizer, é preciso pensar em novas topologias diferenciais da ação. E para isso o conceito de multinaturalismo, de Viveiros de Castro, é um conceito fundamental.

Viveiros de Castro vai falar da necessidade de se fazer proliferar as diversidades, as variações contínuas, o que ele chama de antinarcisismo. "Perspectivismo interespecífico, multinaturalismo ontológico e alteridade canibal" seriam seus elementos. A definição de "multinaturalismo" merece ser retomada em sua totalidade:

a expressão 'multinaturalismo' para designar um dos traços contrastivos do pensamento ameríndio em relação às cos- 
mologias 'multiculturalistas' modernas: enquanto estas se apoiam na implicação mútua entre unicidade da natureza e multiplicidade das culturas - a primeira garantida pela universalidade objetiva dos corpos e da substância, a segunda gerada pela particularidade subjetiva dos espíritos e dos significados -, a concepção ameríndia suporia, ao contrário, uma unidade do espírito e uma diversidade dos corpos. A 'cultura' ou o sujeito seriam aqui a forma do universal, a 'natureza' ou o objeto, a forma do particular. (Castro 27)

Não é por acaso que o autor invoca Latour. A unidade do mundo só é possível por causa da assimetria entre referente e interpretação. Pensar em outra forma de sujeito implica em destruir justamente esse modelo. Coloca-se, então, a necessidade de pensar nas ligações não apenas entre pessoas e línguas, mas entre mundos, e por isso a noção de multinaturalismo é fundamental. Porquê num mundo em que o fluxo de informações é ilimitado, ainda falta pensar como os mundos em que trafegam as informações podem dialogar, como sair das bolhas, como traduzir. É como se estivéssemos diante uns dos outros, mas surdos. Parados diante da superfície, não sabemos como ler os sinais por ela emitidos. Intuímos que há algo além do que percebemos, e que seria útil saber do que se trata, mas não sabemos como. Desse modo, temos acesso a uma infinidade de significantes, mas ficamos presos em nossas ilhas de significados:

O que o perspectivismo afirma, enfim, não é tanto a ideia de que os animais são 'no fundo' semelhantes aos humanos, mas sim a de que eles, como os humanos, são outra coisa 'no fundo': eles têm, em outras palavras, um 'fundo', um 'outro lado'; são diferentes de si mesmos. (Castro 39)

O processo de tradução, no entanto, não pode mais ser concebidos como mero exercício linguístico: "A semelhança das almas não 
implica a homogeneidade ou identidade do que essas almas exprimem ou percebem" (CASTRO 28). Todo o esforço desse artigo foi no sentido de encontrar uma linguagem ontológica para expressar a urgência dos processos tradutórios. Como já dissemos, os itens selecionados das mais diversas culturas e situações para reformular a ideia de sujeito, podem ser relacionados com a realização de outros múltiplos sociais, culturais, psíquicos, enfim, históricos. Usando o vocabulário de Badiou, trata-se de propor novos processos de conta- por-um que reformulem as relações humanas na (e com) a terra. Desse ponto de vista, se substituirmos a palavra "mito" pela palavra "tradução" no trecho abaixo, teremos uma definição precisa do que queremos dizer:

O perspectivismo ameríndio conhece então no mito um lugar geométrico onde a diferença entre os pontos de vista é ao mesmo tempo anulada e exacerbada. Nesse discurso absoluto, cada espécie de ser aparece aos outros seres como aparece para si mesma - como humana -, e entretanto age como se já manifestando sua natureza distintiva e definitiva de animal, planta ou espírito. Ponto de fuga universal do perspectivismo, o mito fala de um estado do ser onde os corpos e os nomes, as almas e as ações, o eu e o outro se interpenetram, mergulhados em um mesmo meio pré-subjetivo e pré-objetivo. (Castro 38)

É pela distância entre mundos, entre corpos, que a tradução deve andar sempre no fio da navalha do equívoco. Não se trata de encontrar uma referência em comum, mas sim equívocos que possam ser partilhados, já que o equívoco é a "alteridade referencial entre conceitos homônimos". Ele "aparece ali como o modo por excelência de comunicação entre diferentes posições perspectivas" (Castro 55).

O Brasil já possui uma infeliz, mas útil, experiência no sentido de compartilhar impossibilidades e transformá-las em potência. Tratasse da experiência da escravidão. Segundo Lilia Schwarcz e Heloísa Starling: 
Os escravizados que chegavam à América falavam línguas distintas, e com frequência as vendas finais no continente rompiam elos culturais e familiares entre eles, ou ao menos essa era a intenção dos clientes interessados em evitar possíveis insurreições e revoltas. (79)

Quer dizer, estar diante de superfícies indecifráveis e perceber a necessidade de fazer contatos apesar da situação extrema em que se encontravam, ou por causa dela, é algo que já aconteceu entre nós. Sem referências em comum, diante da brutalidade e de uma casagrande que tampouco podiam decifrar, a população negra teve de encontrar outras maneiras de se comunicar antes de se entenderem mais efetivamente:

Seja através dos cultos, seja por meio dos cantos e músicas, dos batuques, dos alimentos ou dos vestiários, um processo de aculturação, adaptação e tradução ocorreu nas terras do Novo Mundo e acima de tudo no Brasil (Schwarcz; Starling 80)

Nada pode ser comparado a uma experiência como a da escravidão, mas é possível traçar alguns paralelos. O mundo está diante de um sistema financeiro internacional que nos domina, que brutaliza nossas relações, mas que não entendemos. Tampouco conseguimos nos entender a ponto de estabelecer laços de resistência que interessariam a todos, do trabalhador chinês ao índio Krahô. Desse modo, torna-se necessário um exercício de leitura, de formação de imaginário, que nos permita ir além do aparente estranhamento para a formulação de estratégias eficazes diante dessa gigantesca "casa-grande" que contemplamos sem entender, que tem braços para precarizar as nossas vidas sem que mal esbocemos reação.

Viveiros de Castro invoca Strathern e Wagner numa afirmação que nos parece fundamental: 
Relações intraculturais, ou comparações internas (as 'analogias entre domínios' de Strathern), e relações interculturais, ou comparações externas (a 'invenção da cultura' de Wagner), estão em estrita continuidade ontológica. (CASTRO 53)

Existe, portanto, relação dialética entre internalidades e externalidades. Mais importante, é uma relação ontológica. No entanto, existe uma clivagem, um rompimento ontológico intra/entre culturas e nações. Thomas Piketty diz que o balanço patrimonial dos países desenvolvidos em relação ao resto do mundo é ligeiramente negativo. Por outro lado, o mesmo balanço do lado dos países em desenvolvimento também seria negativo. Que conclusão podemos tirar? "Seríamos possuídos por marte?” (PIKETTY 454). Mas a resposta verdadeira vem em seguida: "a existência de uma massa importante de ativos financeiros não registrados detidos nos paraísos fiscais" (PIKETTY 455). Não sabemos a quem pertencem, como circulam, nem exatamente quanto representa essa massa de ativos. O cidadão comum não tem nenhum acesso a esse mundo das finanças. Mas as instituições que o representa tem um acesso privilegiado ao "nosso" mundo. Estão nos ministérios de economia e nos bancos centrais espalhados pelo mundo. É preciso achar uma linguagem para traduzir e acessar esse rompimento ontológico que temos entre nós. Usando o vocabulário de Badiou, precisamos reformular a singularidade dos múltiplos históricos, por definição incompletos. Para isso, a leitura do multinaturalismo, a tradução possível de mundos diversos desvelando o fundo comum diante do estranhamento exterior, tem de ser transformado em estratégia política. Proponho chamar esse engajamento multinatural de "potência-senzala", fazendo referência clara ao grupo que passou por situação parecida e se reinventou para encontrar caminhos. Diante de instituições incompreensíveis e sofrendo a violência dos braços responsáveis por suprimir qualquer questionamento a essas verdadeiras "casas-grandes" contemporâneas, é fundamental observar experiências de superação. A grande fenda (ontológica) que se abre em nossos seres aguarda ansiosamente. 


\section{Referências}

Badiou, Alain. O Ser e o Evento. Tradução: Maria Luiza X. de A. Borges. $1^{\text {a }}$. Ed. Rio de Janeiro: João Zahar Editor Ltda, 1996.

Castro, Eduardo V. de Metafísicas Canibais. 1 ${ }^{\text {a }}$. Ed. São Paulo, Cosac Naif, 2015.

Kurz, Robert. Razão Sangrenta. Tradução: Fernando R. de Moraes Barros. São Paulo: Hedra, 2010.

Latour, Bruno. Jamais Fomos Modernos. Tradução: Carlos Irineu da Costa. $1^{\text {a }}$. Ed. Rio de Janeiro: Editora 34, 1994.

Meschonnic, Henry. Critique du Rythme. 2a ${ }^{\text {a }}$ Ed. Paris: Verdier, 1982.

Piketty, Thomas. O Capital no Século XXI. Tradução: Mônica de Bolle. $1^{\mathrm{a}}$. Ed. Rio de Janeiro: Intrínseca, 2014.

Shwarcz, Lilia M.; Starling, Heloísa M. Brasil: uma Biografia. 1 ${ }^{\text {a }}$. Ed. São Paulo: Companhia das Letras, 2015.

Strathern, Marilyn. Partial Connections. Oxford: Altamira Press, 2014.

Wagner, Roy. An Anthropology of the Subject. $1^{\mathrm{a}}$. Ed. Berkeley and Los Angeles: The University of California Press, 2001.

Wagner, Roy. The Invention of Culture. Chicago: The University of Chicago Press, 1981.

Recebido em: 10/10/2019

Aceito em: 29/11/2019

Publicado em dezembro de 2019

Leandro T. C. Bastos. E-mail: leandrotcb@hotmail.com

ORCID: http://orcid.org/0000-0002-4570-9094 